\title{
Src Family Kinases Are Required for Limb Trajectory Selection by Spinal Motor Axons
}

\author{
Tzu-Jen Kao, ${ }^{1}$ Elena Palmesino, ${ }^{1}$ and Artur Kania ${ }^{1,2,3}$ \\ ${ }^{1}$ Institut de recherches cliniques de Montréal, Montréal, Quebec H2W 1R7, Canada, ${ }^{2}$ Department of Anatomy and Cell Biology, Division of Experimental \\ Medicine, McGill University, Montréal, Quebec H3A 2B2, Canada, and 'Faculté de médecine, Université de Montréal, Montréal, Quebec H3C 3J7, Canada
}

Signal relay by guidance receptors at the axonal growth cone is a process essential for the assembly of a functional nervous system. We investigated the in vivo function of Src family kinases (SFKs) as growth cone guidance signaling intermediates in the context of spinal lateral motor column (LMC) motor axon projection toward the ventral or dorsal limb mesenchyme. Using in situ mRNA detection we determined that Src and Fyn are expressed in LMC motor neurons of chick and mouse embryos at the time of limb trajectory selection. Inhibition of SFK activity by C-terminal Src kinase (Csk) overexpression in chick LMC axons using in ovo electroporation resulted in LMC axons selecting the inappropriate dorsoventral trajectory within the limb mesenchyme, with medial LMC axon projecting into the dorsal and ventral limb nerve with apparently random incidence. We also detected LMC axon trajectory choice errors in Src mutant mice demonstrating a nonredundant role for Src in motor axon guidance in agreement with gain and loss of Src function in chick LMC neurons which led to the redirection of LMC axons. Finally, Csk-mediated SFK inhibition attenuated the retargeting of LMC axons caused by EphA or EphB over-expression, implying the participation of SFKs in Eph-mediated LMC motor axon guidance. In summary, our findings demonstrate that SFKs are essential for motor axon guidance and suggest that they play an important role in relaying ephrin:Eph signals that mediate the selection of motor axon trajectory in the limb.

\section{Introduction}

In the developing nervous system, axons are guided by signals transmitted to the cytoskeleton through guidance receptors. Src family kinases (SFKs) have been proposed to function in this process (Sasaki et al., 2002; Liu et al., 2007) prompting us to investigate their role in the axon guidance decision executed by motor axons upon limb mesenchyme entry.

SFKs are nonreceptor kinases containing the Src homology (SH) 1 domain containing the catalytic tyrosine kinase domain and a regulatory domain. $\mathrm{SH} 2$ and $\mathrm{SH} 3$ domains function in SFK target recognition and binding (Martin, 2001). SFK activity is inhibited by phosphorylation by the C-terminal Src kinase (Csk) (Klages et al., 1994). Four SFK members, Src, Fyn, Yes, and Lyn are expressed in the CNS (Thomas and Brugge, 1997) and mediate differentiation, axon outgrowth, fasciculation, and guidance (Kuo et al., 1997; Morse et al., 1998; Hoffman-Kim et al., 2002; Robles et al., 2005). The evidence for SFK function in axon guidance stems from invertebrate studies demonstrating SFK involvement in Wnt5/derailed-mediated axon repulsion in Drosophila

Received Jan. 16, 2009; revised March 16, 2009; accepted April 1, 2009.

This work was supported by a grant from the Canadian Institutes of Health Research (Institute of Genetics and Institute of Neurosciences, Mental Health, and Addiction) to A.K. (MOP-77556 and IG-74068). We thank JeanPhilippe Gratton for the Src mutant mice, Uwe Drescher for the Csk::GFP expression construct, Francoise Helmbacher for the SrCY527F and SrcDN expression constructs, Hitoshi Okamoto for the zCrest2-pls/1-PLAP expression construct, and Keith Murai for the EphA4 and EphA4Y602E expression constructs. We also thank André Veillette for the Src antibody, Frédéric Charron and Keith Murai for comments on this manuscript, Julie Cardin and Meirong Liang for technical assistance, and Monique Bernier and Lise Delorme for secretarial assistance.

Correspondence should be addressed to Artur Kania, Institut de recherches cliniques de Montréal, 110, avenue

des Pins Ouest, Montréal, QC H2W 1R7, Canada. E-mail: artur.kania@ircm.qc.ca.

D0I:10.1523/JNEUROSCI.0265-09.2009

Copyright $\odot 2009$ Society for Neuroscience $\quad$ 0270-6474/09/295690-11\$15.00/0 and netrin/UNC-5-mediated growth cone guidance in C. elegans (Itoh et al., 2005; Wouda et al., 2008). In addition to Netrin signaling, SFKs have been proposed to mediate ephrin-A:EphAmediated axon guidance in vertebrates, possibly through effectors such as ephexin and Nck (Knöll and Drescher, 2004; Meriane et al., 2004; Fawcett et al., 2007; Yue et al., 2008). However, our complete understanding of SFKs' function in axon guidance is hindered by their functional redundancy (Stein et al., 1994) and few accessible in vivo axon guidance decisions in which SFKs' role can be assayed with precision.

One relatively simple system suited for the study of axon guidance signaling is composed by spinal motor axon trajectories in the limb. Limb-innervating lateral motor column (LMC) neurons are divided into medial and lateral divisions, invariantly innervating ventral and dorsal limb muscles, respectively (Landmesser, 1978; Lance-Jones and Landmesser, 1981; Luria and Laufer, 2007). The LIM homeodomain transcription factors Isl1 in medial and Lim1 in lateral LMC neurons promote, respectively, tyrosine kinase receptor EphB1 and EphA4 expression. Their cognate ligands, ephrin-B2 and ephrin-A5, are expressed in the dorsal and ventral limb, and repulsive ephrin:Eph interactions have been proposed to result in the selection of appropriate limb nerve trajectory (Tsuchida et al., 1994; Helmbacher et al., 2000; Eberhart et al., 2002; Kania and Jessell, 2003; Luria et al., 2008). This simple choice executed by LMC axons is an ideal in vivo system in which to functionally dissect the molecular cascade relaying axon guidance receptor signaling.

Here we show that Src and Fyn are expressed in LMC neurons and SFK activity inhibition by Csk over-expression or Src mutation perturbs LMC axon trajectory selection. The over- 
expression of constitutively active or dominant negative Src results in opposite effects on LMC axon trajectory choice. Finally, Eph receptor-mediated redirection of LMC axons is attenuated by SFK function inhibition or by mutation of a Src binding site in EphA4 suggesting that SFKs are required for ephrin:Eph mediated LMC axon trajectory selection.

\section{Materials and Methods}

Chick and mouse embryo preparations. Fertilized chick eggs (Couvoir Simetin) were stored for a maximum of 1 week at $18^{\circ} \mathrm{C}$, incubated at $38^{\circ} \mathrm{C}$ and staged according to standard protocols (Hamburger and Hamilton, 1951). The genotype of mouse embryos was determined as described (Soriano et al., 1991). In brief, tails of mouse e12.5 embryos were digested with $100 \mu \mathrm{g} / \mathrm{ml}$ proteinase K in SDS tail buffer (100 mm Tris pH 8.5, $5 \mathrm{~mm}$ EDTA, $200 \mathrm{~mm} \mathrm{NaCl}, 0.2 \% \mathrm{SDS}$ ) at $55^{\circ} \mathrm{C}$ overnight. The extracted DNA was precipitated by isopropanol, washed with $70 \%$ ethanol, and resuspended in $\mathrm{ddH}_{2} \mathrm{O}$. PCR was performed using Qiagen Master Mix and the following primers: common primer (5'-AGCAACAAGAGCAAGCCCAAGGAC-3'), Src (5'-TCATAGCCGAATAGCCTCTCCAC-3'), and WT (5'-GTGACGGTGTCCGAGGAGTTGAAG-3'). PCR products were then visualized on a $2 \%$ agarose gel after gel electrophoresis $\left(\mathrm{Src}^{+/+}\right.$ $=200 \mathrm{bp}, \mathrm{Src}^{-1-}=450 \mathrm{bp}, \mathrm{Src}^{+-}=$both $200 \mathrm{bp}$ and $450 \mathrm{bp}$ ).

Molecular biology. The Csk expression plasmid was generated by BsrGI digestion of Csk::GFP (Knöll and Drescher, 2004) and subcloning of the $1.8 \mathrm{~kb}$ fragment into the Asp718 site of $p C A G G S / S E$. The $e[$ Isl1] ::GFP plasmid was generated by insertion of a $0.65 \mathrm{~kb} E c o$ RI fragment of $z$ Crest2-pIsl1-PLAP containing the enhancer of Isl1 ( $e$ [Isl1]) (Uemura et al., 2005) into pBluescript (Invitrogen). The $0.7 \mathrm{~kb}$ SalI-NotI fragment of pBS::e[Isl1] was subcloned into the XbaI site of pTATAGFP (Lee et al., 2004). The characterization of other expression constructs, including EphA4::GFP, EphA4, EphA4Y602E, EphB2::GFP, SrcY527F, and SrcDN, has been described (Erpel et al., 1995; Kania and Jessell, 2003; Zhou et al., 2007).

In situ hybridization cRNA probes were obtained as follows: target sequences amplification primers were designed using Primer3 V. 0.4.0 software (Rozen and Skaletsky, 2000) and the probe size was set at 600 $800 \mathrm{bp}$. One-step RT-PCR was performed (Qiagen) using designed primers containing T7 polymerase promoters (Invitrogen) to make and amplify cDNA template from chick $\mathrm{HH}$ st. $25 / 26$ or mouse e11.5 pooled brain RNA. The PCR product was purified by gel electrophoresis in $1 \%$ agarose gel and gel extraction using QIAquick gel extraction kit (Qiagen). The purified DNA was then reamplified by PCR. The yield of DNA was estimated by the Low DNA Mass Ladder (Invitrogen) after gel electrophoresis. DIG-labeled RNA probes were synthesized by in vitro transcription with T7 RNA polymerase using DIG RNA labeling kit (Roche). All probes were verified by sequencing. The source of sequence and the recognized region for each probe are described as follows: chick $\mathrm{Src}$ (NM_205425, 450-1150), chick Fyn (NM_205349, 942-1636), chick Yes (NM_205301, 246-912), chick Lyn (NM_001006390, 775-1428), chick Csk (Sabe et al., 1992, 450-1150), mouse Src (NM_009271, 728-1463), mouse Fyn (NM_008054, 333-1087), mouse Yes (NM_009535, 6901474), mouse Lyn (NM_010747, 623-1307), mouse Csk (Klages et al., 1994, 173-815). The details of Isl1 and Lim1 probes have been described previously (Tsuchida et al., 1994).

Chick in ovo electroporation. Chick spinal cord electroporation of expression plasmids was performed at $\mathrm{HH}$ st. 18/19, generally as described (Momose et al., 1999; Luria et al., 2008). In brief, a 5-10 $\mu \mathrm{g} / \mu \mathrm{l}$ solution of plasmid DNA in TE buffer pH 7.5 [10 mm Tris-Cl (Fisher Scientific) and $1 \mathrm{~mm}$ EDTA (Invitrogen)] was injected into the lumbar neural tube through a small eggshell window under a Discovery V12 stereomicroscope (Zeiss). Lower bodies of chick embryos were then electroporated with platinum/iridium electrodes (FHC) and the TSS20 Ovodyne electroporator (Intracel; settings: $30 \mathrm{~V}, 5$ pulses $50 \mathrm{~ms}$ wide in a $1 \mathrm{~s}$ interval). Shell windows were sealed with Parafilm (Pechiney Plastic Packaging Company) and incubated at $38^{\circ} \mathrm{C}$ until harvesting at $\mathrm{HH}$ st. $28 / 29$. The efficiency of electroporation varied between 5 and $30 \%$ of total LMC neurons electroporated depending on the construct and DNA concentration used. When the Csk expression plasmid was coelectroporated with other plasmids, its concentration was at least three times that of other plasmids to ensure high efficiency of coexpression. SrcY527F, SrcDN, EphA4, or EphA4Y602E expression plasmids were coelectroporated with $G F P$ at a 3:1 weight ratio.

HRP retrograde labeling of motor neurons. Retrograde labeling of chick and mouse motor neurons was performed as described (Luria et al., 2008). In brief, chick HH st. $28 / 29$ embryos were harvested and incubated in Tyrode's solution ( $139 \mathrm{~mm} \mathrm{NaCl}, 3 \mathrm{~mm} \mathrm{KCl}, 17 \mathrm{~mm} \mathrm{NaHCO} 3,12$ mm glucose, $12 \mathrm{~mm} \mathrm{CaCl}_{2}, 1 \mathrm{~mm} \mathrm{MgCl}_{2}$; Fisher Scientific) at room temperature (RT) and aerated with $95 \%$ air and $5 \% \mathrm{CO}_{2}$. The retrograde tracer used was a $20 \%$ solution of HRP (Roche) made by dissolving 100 mg of HRP in $450 \mu \mathrm{l}$ of PBS (137 mm NaCl, $2.7 \mathrm{~mm} \mathrm{KCl}, 4.3 \mathrm{~mm}$ $\mathrm{Na}_{2} \mathrm{HPO}_{4}, 1.47 \mathrm{~mm} \mathrm{KH}_{2} \mathrm{PO}_{4}$ ) with $50 \mu$ l of $10 \%$ lysophosphatidylcholine (Fluka) in PBS. The HRP solution was injected into either dorsal or ventral hindlimb shank musculature of chick embryos. For mouse retrograde labeling, e12.5 embryos were dissected at thoracic level and incubated in aerated DMEM/F12 medium (Invitrogen) at RT. The HRP solution (as above) was injected into either dorsal or ventral forelimb proximal muscle group and embryos were incubated at $32^{\circ} \mathrm{C}$ under an infrared lamp and aerated with $95 \%$ air and $5 \% \mathrm{CO}_{2}$. Fresh media were added every $30 \mathrm{~min}$ for $5 \mathrm{~h}$.

In situ mRNA detection and immunostaining. Chick and mouse embryos were fixed in a $4 \%$ solution of paraformaldehyde (Sigma) in PBS, equilibrated with $30 \%$ sucrose in PBS, embedded in O.C.T. (Sakura Finetek), and stored at $-80^{\circ} \mathrm{C}$. Twelve micrometer sections were collected using a Leica cryostat microtome.

In situ mRNA detection was performed as described (SchaerenWiemers and Gerfin-Moser, 1993; Kania and Jessell, 2003). In brief, tissue sections were first fixed in $4 \%$ solution of paraformaldehyde in PBS for $10 \mathrm{~min}$ at RT, washed three times with PBS for $5 \mathrm{~min}$, and digested in Proteinase K solution [ $1 \mu \mathrm{g} / \mathrm{ml}$ Proteinase K (Roche) in $6.25 \mathrm{~mm}$ EDTA pH 8.0 (Invitrogen) and $50 \mathrm{~mm}$ Tris pH 7.5 (Fisher Scientific)]. Samples were acetylated for $10 \mathrm{~min}$ by immersion in a mixture of $6 \mathrm{ml}$ of triethanolamine (Sigma), $500 \mathrm{ml}$ of double-distilled $\mathrm{H}_{2} \mathrm{O}$ and $1.30 \mathrm{ml}$ of acetic anhydride (Sigma). After PBS washes, samples were incubated with hybridization buffer [ $50 \%$ formamide, $5 \times$ SSC $(20 \times$ SSC is $3 \mathrm{M} \mathrm{NaCl}, 0.3 \mathrm{M}$ $\mathrm{NaAc}$ ), $5 \times$ Denhardt's (Sigma) and $500 \mu \mathrm{g} / \mathrm{ml}$ Salmon sperm DNA (Roche)] for $2 \mathrm{~h}$ at RT followed by incubation overnight at $72^{\circ} \mathrm{C}$ with DIG-labeled RNA probes (see above) in the hybridization buffer at a concentration of $2-5 \mathrm{ng} / \mu \mathrm{l}$. After hybridization, samples were immersed in $5 \times$ SSC at $72^{\circ} \mathrm{C}$, followed by two washes in $0.2 \times$ SSC at $72^{\circ} \mathrm{C}$ for 45 min each and $0.2 \times$ SSC at RT for $5 \mathrm{~min}$. Tissues were then rinsed with B1 buffer [0.1 M Tris pH 7.5 and $0.15 \mathrm{M} \mathrm{NaCl}$ (Fisher Scientific)] for $5 \mathrm{~min}$, blocked with B2 buffer (10\% heat inactivated horse serum in B1) for $1 \mathrm{~h}$ at RT, and incubated with anti-DIG antibody (1:5000 in B2, Roche) overnight at $4^{\circ} \mathrm{C}$. Samples were then rinsed with $\mathrm{B} 1$ and equilibrated with B3 buffer [0.1 M Tris pH 9.5, $0.1 \mathrm{M} \mathrm{NaCl}, 0.05 \mathrm{M} \mathrm{MgCl}_{2}$ (Fisher Scientific)]. To detect bound anti-DIG antibodies, samples were incubated with B4 buffer [100 mg/Ml NBT, $50 \mathrm{mg} / \mathrm{Ml} \mathrm{BCIP} \mathrm{(Roche)} \mathrm{and} 400 \mathrm{~mm}$ Levamisol (Sigma) in B3] in the dark. The reaction was stopped by immersion in $\mathrm{H}_{2} \mathrm{O}$.

For immunostaining, sectioned tissue was first washed in PBS, incubated in blocking solution [ $1 \%$ heat inactivated horse serum in $0.1 \%$ Triton-X/PBS (Sigma)] for $5 \mathrm{~min}$, followed by incubation overnight at $4^{\circ} \mathrm{C}$ in selected primary antibodies diluted in blocking solution. The following primary antibodies were used: guinea pig and mouse anti-Isl1 (1:1000 and 1:100, Tsuchida et al., 1994), rabbit anti-Lim1/2 (1:100, Tsuchida et al., 1994), rabbit anti-FoxP1 (1:1000, Abcam), guinea pig anti-FoxP1 (1:1000, Dasen et al., 2008), sheep and rabbit anti-GFP (1: 1000, Molecular Probes), rabbit anti-EphA4 (1:1000, Santa Cruz Biotechnology), goat anti-EphB1 (1:500, Santa Cruz Biotechnology), goat anti-HRP (1:2000, Jackson ImmunoResearch Laboratory), mouse antimouse $165 \mathrm{kDa}$ neurofilament (1:500, Dodd and Jessell, 1988), and mouse anti-Src (1:1000, kindly provided by A. Veillette, Institut de recherches cliniques de Montréal, Montréal, QC, Canada). After the incubation in primary antibodies, samples were washed with PBS and incubated with appropriate secondary antibodies for $1 \mathrm{~h}$ at RT. The following secondary antibodies were used: $\mathrm{Cy} 3-$ (or Cy-5-) conjugated AffiniPure Donkey anti-mouse (rabbit, goat, or guinea pig) IgG (1:1000 for Cy3-, 
1:500 for Cy5-secondary antibodies, Jackson ImmunoResearch Laboratory), Alexa Fluo 488 donkey anti-mouse (rabbit, or sheep) IgG (1: 1000, Molecular Probes).

For ephrin-A5-Fc overlays, tissue sections were incubated in blocking solution (see above) for $5 \mathrm{~min}$ and then incubated overnight at $4^{\circ} \mathrm{C}$ with recombinant human ephrin-A5-Fc chimera $(10 \mu \mathrm{g} / \mathrm{ml}$ in PBS, R\&D Systems). Samples were then washed with PBS and fixed with $4 \%$ paraformaldehyde in PBS for 2 min. After PBS rinses, samples were incubated with preheated PBS at $72^{\circ} \mathrm{C}$ for $3 \mathrm{~h}$ to inactivate endogenous alkaline phosphatases. Tissues were then cooled to RT in PBS and incubated with antihuman IgG conjugated with alkaline phosphatase secondary antibody (1:1000, Promega) for $1 \mathrm{~h}$. After PBS washes, samples were incubated with B3 (see above) for 5 min followed by detection of bound antibody in B4 (see above).

Image quantification. Images were acquired using a Leica DM6000 microscope or a Zeiss LSM confocal microscope with Volocity imaging software (Improvision). GFP-labeled axonal projections were quantified by combining over threshold pixel counts in limb section images containing limb nerves (10-15 of $12 \mathrm{mi}-$ crometer limb sections from each embryo) us-
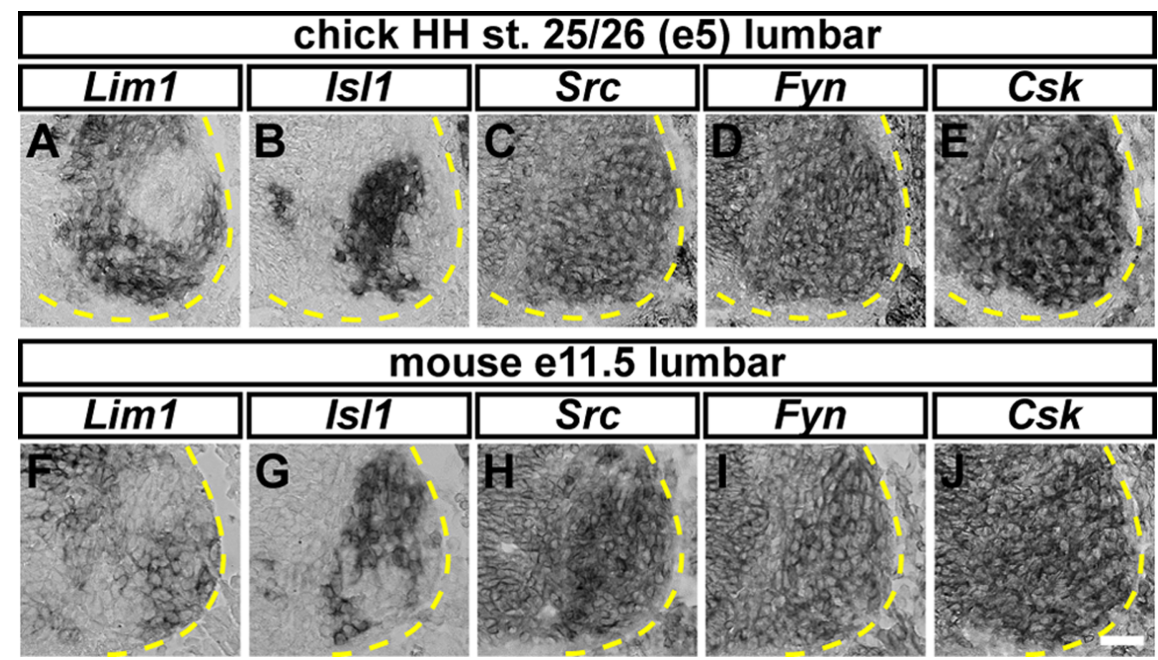

Figure 1. Expression of SrC, Fyn, and Csk in chick and mouse LMC motor neurons. A-J, Detection of mRNA in consecutive sections of the spinal cord. All chick sections $(\boldsymbol{A}-\boldsymbol{E})$ are $\mathrm{HH}$ st. $25 / 26$ lumbar spinal cord; all mouse sections $(\boldsymbol{F}-\boldsymbol{J})$ are e11.5 lumbar spinal cord. $\boldsymbol{A}, \boldsymbol{B}$, Detection of $\operatorname{Lim} 1$ and $/ s / 1 \mathrm{mRNA}$ in the chick spinal cord. $\operatorname{Lim} 1(\boldsymbol{A})$ and $/ s / 1(\boldsymbol{B})$ expression highlights lateral and medial LMC motor neurons, respectively. $\boldsymbol{C}, \boldsymbol{D}$, Detection of $\operatorname{SrC}(\boldsymbol{C})$ and $F y n(\boldsymbol{D}) \mathrm{mRNA}$, in both medial and lateral chick LMC neurons. $\boldsymbol{E}$, Detection of (sk mRNA in LMC in both medial and lateral chick LMC neurons. $\boldsymbol{F}$, G, Detection of $\operatorname{Lim} 1(\boldsymbol{F})$ and $/ s / 1(\boldsymbol{G})$ mRNA in mouse LMC motor neurons. $\boldsymbol{H}-\boldsymbol{J}$, Detection of $\operatorname{SrC}(\boldsymbol{H})$, Fyn $(\boldsymbol{I})$, and $(s k(J)$ mRNA in medial and lateral mouse LMC neurons. Scale bar, $25 \mu \mathrm{m}(\boldsymbol{A}-\boldsymbol{J})$. ing Photoshop (Adobe). The dorsal or ventral limb nerve was selected by gating on the neurofilament channel and using the Lasso Tool, and pixel counts from the threshold to the maximal level were those indicated in the Histogram window of the GFP channel. Motor neuron numbers were quantified by combining cell counts of a series of spinal cord section images (5-10 of 12 micrometer limb sections from each embryo).

Statistical analysis. Data from the experimental replicate sets were evaluated using Microsoft Excel or Aabel (Gigawiz). Means of the combined proportions or cell numbers were compared with Student's unpaired $t$ tests with the threshold for statistical significance set at 0.05 .

\section{Results}

\section{Src and Fyn expression in LMC neurons}

To examine SFK function in motor axon guidance, we first determined whether Src, Fyn, Yes, and Lyn are expressed in LMC at the time of axon growth into the limb mesenchyme which occurs between Hamburger-Hamilton stage (HH st.) 25 and 27 in chick and between the embryonic day (e) 10.5 and e 11.5 in mouse (Hamburger and Hamilton, 1951; Tosney and Landmesser, 1985; Kania et al., 2000). Thus, we surveyed SFK expression in the lumbar spinal cord of $\mathrm{HH}$ st. 25/26 chick embryos and both brachial/cervical and lumbar spinal cord of e11.5 mouse embryos. LMC neurons were identified by the expression of the medial LMC neuron marker, Isll, and the lateral LMC neuron marker, Lim1 (Fig. 1A,B,F,G; supplemental Fig. S1, available at www.jneurosci.org as supplemental material). Src and Fyn mRNA were found to be highly expressed in both medial and lateral LMC motor neurons in chick and mouse embryos (Fig. $1 C, D, H, I$; supplemental Fig. S4, available at www.jneurosci.org as supplemental material). In addition, we also detected the expression of Src protein in LMC neurons (supplemental Fig. S5, available at www.jneurosci.org as supplemental material). No obvious difference of Src and Fyn expression levels was observed between medial and lateral LMC in chick and mouse and between the brachial and the lumbar spinal cord of mouse embryos (Fig. 1; supplemental Fig. S1, available at www.jneurosci.org as supplemental material). The expression of the other two SFK members, Yes and Lyn, was not detected in neither chick nor mouse LMC neurons (sup-

plemental Fig. S1, available at www.jneurosci.org as supplemental material).

To determine whether Csk, the endogenous inhibitor of SFKs, might participate in regulation of Src and Fyn activity in LMC neurons we also examined the spinal cord expression profile of Csk mRNA. We observed a strong expression of Csk in both medial and lateral LMC neurons at the lumbar level of chick $\mathrm{HH}$ st. 25/26 spinal cord (Fig. 1E). Csk mRNA was also expressed in LMC neurons at both brachial and lumbar levels of mouse e11.5 spinal cord (Fig. 1J; supplemental Fig. S1, available at www. jneurosci.org as supplemental material). No obvious difference in $C s k$ expression levels was observed between medial and lateral LMC in chick and mouse and between the brachial and the lumbar spinal cord of mouse embryos (Fig. 1E,J; supplemental Fig. $\mathrm{S} 1$, available at www.jneurosci.org as supplemental material; data not shown). These results demonstrate that Src, Fyn and their inhibitor Csk are coexpressed by LMC neurons at the time of motor axon entry into the limb mesenchyme.

\section{Csk-mediated SFK inhibition results in aberrant LMC axon trajectory choice}

The expression of Src and Fyn in LMC neurons suggests that these genes may function in the selection of limb mesenchyme trajectory by LMC axons. To test this idea, we inhibited Src and Fyn function by over-expression of a GFP-tagged Csk isoform from an expression plasmid ( $C s k:: G F P$ ) in LMC neurons at the time of their entry into the limb mesenchyme. Previous studies have confirmed the high efficiency of the Csk::GFP fusion protein in SFK activity inhibition (Knöll and Drescher, 2004). To examine the consequences of SFK function block on LMC axon guidance, we used in ovo electroporation to introduce Csk::GFP into lumbar LMC neurons of HH st. 18/19 chick embryos, before motor axons have entered the hindlimb mesenchyme, and examined $\mathrm{GFP}^{+}$ motor axons in dorsal and ventral nerve branches at HH st. 28/29 (Kania and Jessell, 2003). Over-expression of Csk::GFP did not change the number of neurons expressing the LMC marker FoxP1 nor did it change the proportions of lateral (FoxP1 ${ }^{+}$, 


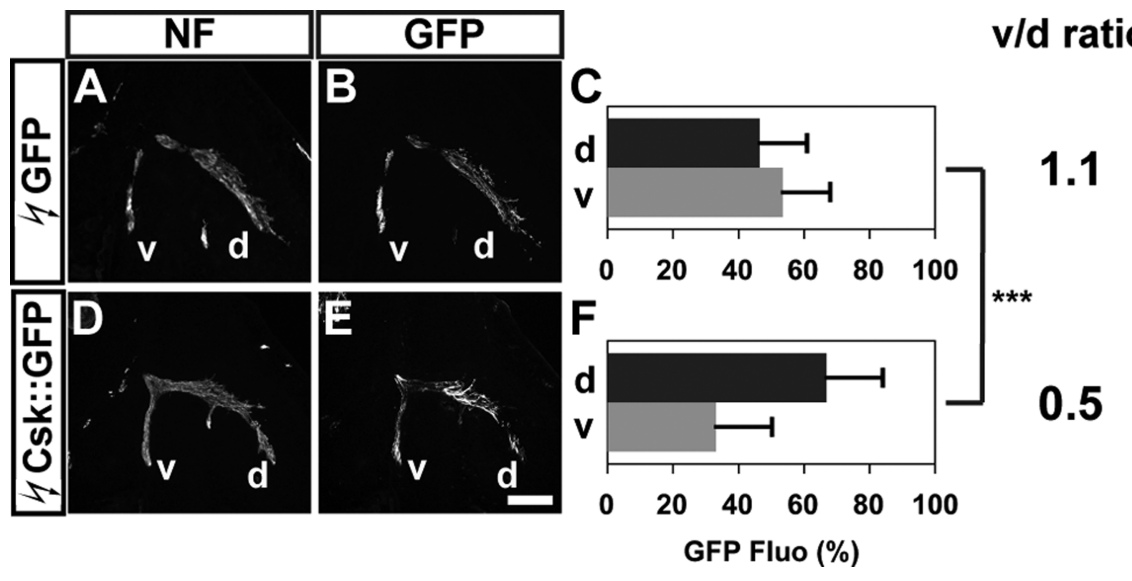

Figure 2. SFK inhibition by Csk overexpression redirects LMC motor axons into the dorsal limb nerve. $\boldsymbol{A}, \boldsymbol{D}$, Neurofilament detection in the limb nerves of chick HH st. 28/29 embryos electroporated with GFP $(\boldsymbol{A})$ or Csk::GFP (D) expression plasmids. $\boldsymbol{B}, \boldsymbol{E}$, GFP detection in the limb nerves of chick HH st. 28/29 embryos electroporated with GFP (B) or CSk::GFP $(\boldsymbol{E})$ expression plasmids. $\boldsymbol{C}$, $\boldsymbol{F}$, Quantification of $\mathrm{GFP}^{+}$axons within dorsal and ventral limb nerves expressed as a percentage of total GFP ${ }^{+}$axons [GFP Fluo (\%)]. In GFP electroporated embryos, $47 \pm 14 \%$ of GFP ${ }^{+}$axons were detected in the dorsal limb nerves, and $53 \pm 14 \%$ of GFP ${ }^{+}$ axons were detected in the ventral limb nerves, resulting in a $\mathrm{v} / \mathrm{d}$ ratio [(average ventral GFP Fluo \%)/(average dorsal GFP Fluo \%)] of 1.1 (C). In (sk::GFP electroporated embryos, $68 \pm 17 \%$ of GFP ${ }^{+}$axons were detected in the dorsal limb nerves and $32 \pm 17 \%$ of GFP ${ }^{+}$axons were detected in the ventral limb nerves, resulting in a $\mathrm{v} / \mathrm{d}$ ratio of $0.5(\boldsymbol{F})$. Number of embryos quantified: $\boldsymbol{C}, n=$ $10 ; \boldsymbol{F}, n=12$. Proportions of GFP ${ }^{+}$axons in (Sk::GFP expressing embryos and those in GFP expressing embryos are significantly different $(p<0.001$ ) using Student's unpaired $t$ test. $v / d$ ratio $=$ (average ventral GFP Fluo \%)/(average dorsal GFP Fluo \%); NF, neurofilament; d, dorsal; v, ventral. Error bars indicate SD. ${ }^{* *} p<0.001$; all values are expressed as mean \pm SD. Scale bar: $(\boldsymbol{A}, \boldsymbol{B}$, D, E), $200 \mu \mathrm{m}$.

Isl $\left.1^{-}\right)$or medial $\left(\mathrm{FoxP}_{1}{ }^{+}, \mathrm{Isl}^{+}{ }^{+}\right.$) LMC neurons when compared with embryos electroporated with a control GFP expression plasmid (supplemental Fig. S2, available at www.jneurosci.org as supplemental material; $51 \%$ vs $49 \%$ for medial and $49 \%$ vs $51 \%$ for lateral LMC neurons; Student's $t$ test, $p=0.540$ ). Quantification of $\mathrm{GFP}^{+} \mathrm{LMC}$ neurons also indicated nearly equal proportions of Csk::GFP expression in both LMC divisions compared with controls (supplemental Fig. S2, available at www.jneurosci.org as supplemental material; $54 \%$ for medial and $46 \%$ for lateral LMC neurons; Student's $t$ test, $p=0.895$ ). In addition, the expression of EphA4 in LMC neurons and their axons and the expression of EphB1 in LMC axons were not affected by Csk::GFP over-expression, and LMC axons entered the dorsal and ventral limb nerves on schedule (supplemental Fig. S2, available at www.jneurosci.org as supplemental material; data not shown).

To determine whether blocking SFK function affected the choice of limb trajectory, we quantified the proportions of GFP ${ }^{+}$ axons in the dorsal and ventral divisional limb nerve branches by integrating fluorescence intensities of a series of hindlimb section images in multiple embryos for each experimental condition (Kania and Jessell, 2003; Luria et al., 2008; see Materials and Methods for detail). In embryos electroporated with control GFP expression plasmid, $47 \%$ of $\mathrm{GFP}^{+}$axons were detected in the dorsal and $53 \%$ in the ventral nerve branches, and the ratio of $\mathrm{GFP}^{+}$axons between ventral and dorsal branches (v/d ratio) was 1.1 (Fig. 2A-C). In embryos electroporated with Csk::GFP, significantly higher proportions of $\mathrm{GFP}^{+}$axons were observed in the dorsal nerve branches when compared with control embryos: $68 \%$ of the $\mathrm{GFP}^{+}$axons were detected in the dorsal and $32 \%$ in the ventral branches, and the v/d ratio decreased to 0.5 (Fig. $2 D-F$; Student's $t$ test, $p<0.001$ ). These findings suggest that SFK inhibition by Csk causes a significantly greater proportion of LMC motor axons to enter the dorsal limb.

Two possible scenarios could explain the increased proportion of LMC neurons projecting into the dorsal nerve branch when SFK function is inhibited: some medial LMC axons might enter the dorsal limb nerve, or both medial and lateral LMC axons inappropriately project into both limb nerves but with a greater proportion of medial LMC axons projecting into the dorsal limb nerve. In either case, we expected a loss of fidelity of medial LMC trajectory selection caused by SFK inhibition. To determine whether the Cskmediated inhibition of SFKs results in redirection of medial LMC axons into the dorsal limb mesenchyme, we coelectroporated an untagged Csk expression plasmid with the e[Isl1]::GFP promoter fusion plasmid, which specifically labels medial LMC motor neurons and their axons (supplemental Fig. S3, available at www. jneurosci.org as supplemental material, detailed characterization of $e[$ Isl 1$]:: G F P)$, and as controls, the $e[$ Isl1]::GFP plasmid. In embryos electroporated with $e[$ [sl1]:: GFP, GFP alone or Csk and $e[I s l]:: G F P$, the number of medial or lateral LMC neurons were not significantly changed when compared with embryos electroporated with the GFP expression plasmid (supplemental Fig. S3, available at www.jneurosci.org as supplemental material). We then assessed the proportions of LMC axons projecting in dorsal and ventral nerves: in $e\left[\right.$ Isl1]::GFP electroporated embryos, $90 \%$ of $\mathrm{GFP}^{+}$axons were detected in the ventral nerve branches and the v/d ratio was 9.0 (Fig. $3 A-C)$. As in controls, GFP expression was strongly biased to medial LMC neurons in embryos coelectroporated with Csk and $e[I s l]:: G F P$ (supplemental Fig. S3, available at www.jneurosci.org as supplemental material; $89 \%$ for $\mathrm{GFP}^{+}$medial and $11 \%$ for $\mathrm{GFP}^{+}$lateral LMC neurons; Student's $t$ test, $p<0.001$ vs GFP controls). However, in the limb, $44 \%$ of $\mathrm{GFP}^{+}$axons were observed in the dorsal divisional nerve branches and $56 \%$ in the ventral nerve branches (Fig. 3D-F; a v/d ratio of 1.3). This ratio was significantly different from $e[$ Isl1]::GFP electroporated control embryos (Fig. $3 A-C$; Student's $t$ test, $p<0.001$ ) indicating that SFK inhibition by Csk results in apparent randomization of the limb trajectory choice made by medial LMC axons.

\section{Asymmetric SFK inhibition sensitivity of the LMC trajectory choice}

The $\mathrm{GFP}^{+}$axon counting experiments do not allow us to compare the extent to which both medial and lateral divisions are sensitive to SFK loss of function. To determine whether SFK function is required for the selection of appropriate lateral LMC axon trajectory, we retrogradely labeled LMC neurons by HRP tracer injection into the ventral shank muscles of HH st. 28/29 embryos in which LMC neurons were electroporated with Csk::GFP or GFP expression plasmids. We determined the divisional identity of labeled LMC neurons by their Isl1 and Lim1 expression status. In GFP expressing embryos, $6 \%$ of electroporated $\mathrm{HRP}^{+}$LMC neurons were lateral LMC $\left(\mathrm{Liml}^{+}\right)$neurons, reflecting occasional pathfinding errors made by LMCl neurons and experimental error (Kania and Jessell, 2003; Luria and Laufer, 2007; Luria et al., 2008). In contrast, in Csk::GFP electroporated embryos, lateral $\mathrm{LMC}\left(\mathrm{Lim}^{+}\right)$neurons made up a significantly higher proportion of electroporated $\mathrm{HRP}^{+}$LMC neurons $(17 \%)$ (Fig. $4 I-P$; Student's $t$ test, $p<0.05$ ) indicating that SFK 
inhibition leads to a loss of fidelity of lateral LMC axon trajectory selection.

To directly compare the effect of SFK inhibition on lateral LMC axon trajectory selection to medial LMC axon trajectory selection, we also retrogradely labeled LMC neurons by HRP injection into dorsal shank muscles of $\mathrm{HH}$ st. 28/29 embryos in which LMC neurons expressed Csk::GFP or GFP. Our analysis of axon trajectory selection by $\mathrm{GFP}^{+}$axon quantification suggests that when SFK activity is inhibited, the dorsoventral limb trajectory selection by medial LMC axon projections is apparently randomized resulting in 50\% of medial LMC axons (53\% of total LMC axons), or $26.5 \%(53 \% / 2)$ of total LMC axons, projecting into the dorsal limb. Thus, we expected that if medial LMC axons in which the SFK activity is inhibited select a dorsoventral limb nerve at random, $36 \%[26.5 \% /(47 \%+26.5 \%)]$ of LMC neurons labeled by dorsal limb HRP injections would be medial LMC neurons. Indeed, in embryos electroporated with Csk::GFP and with HRP injected into dorsal shank muscles, $33 \%$ of $\mathrm{HRP}^{+}$electroporated LMC neurons were medial LMC (Isl1 ${ }^{+}$) neurons, which was a significantly higher proportion than that detected in GFP electroporated control embryos (8\%) (Fig. $4 A-H$; Student's $t$ test, $p<0.001$ ). These observations confirm that SFK inhibition results in a loss of fidelity of limb trajectory choice by LMC axons, and that medial LMC axons rely on SFK activity to a greater extent than lateral LMC axons.

\section{Limited redundancy of SFK function in mouse LMC axon trajectory selection}

To determine the degree of SFK functional redundancy in LMC neurons in the selection of appropriate limb trajectory, we examined the LMC axon trajectory in $\operatorname{Src}$ mutant mice (supplemental Fig. S4, available at www.jneurosci.org as supplemental material; Soriano et al., 1991). The specification and survival of LMC motor neurons, expression of EphA4 protein in lateral LMC neurons and EphB1 mRNA in medial LMC neurons, as well as the timing of axon outgrowth were normal in $\mathrm{Src}^{-/-}$mice compared with wild type littermates (supplemental Fig. S4, available at www.jneurosci.org as supplemental material; data not shown).

To trace the trajectory of LMC axons, we injected HRP into the dorsal or ventral forelimb proximal muscle group, which is still not developed into distinct muscles at this stage (Kania et al., 2000), of e12.5 Src ${ }^{-1-}$ and wild type littermate embryos and quantified the proportions of tracer-filled LMC neurons that expressed Isl1 and Lim 1. In dorsally filled $\mathrm{Src}^{-/-}$embryos, 36\% of HRP labeled LMC neurons were medial LMC (Isl1 ${ }^{+}$) neurons, compared with 5\% labeled in control embryos (Fig. 5A-F; Student's $t$ test, $p<0.001)$. In ventrally filled $\mathrm{Src}^{-1-}$ embryos, $15 \%$ of HRP labeled LMC neurons were lateral LMC ( $\mathrm{Lim} 1^{+}$) neurons, compared with $4 \%$ labeled in control embryos (Fig. 5G-L; Student's $t$ test, $p<0.05)$. These findings demonstrate that Src function is required for the selection of appropriate LMC axon trajectory and that the dependence on Src function is different between medial and lateral LMC neurons.

\section{Gain and loss of Src function affects LMC axon trajectory} selection in chick

To further characterize the role of Src in LMC axon projection, we examined the effect of Src gain and loss of function on LMC axon trajectory selection in chick. To do this, we used a plasmid encoding the constitutively active Src mutant, SrcY527F, where the Csk binding site at the regulatory C-terminal tyrosine residue is mutated (Y527F; Erpel et al., 1995), and a plasmid encoding the dominant negative mutant of Src, SrcDN, containing the Y527F mutation and a kinase domain catalytic site mutation (K295M; Cursi et al., 2006). The $\operatorname{SrcDN}$ double point mutation is a more efficient inhibitor of Src activity than $\operatorname{SrcK} 295 \mathrm{M}$ alone because this mutant can interact with its normal target proteins through SH2 and SH3 domains but is devoid of enzymatic activities and thus competes with endogenous activated SFKs (Fresno Vara et al., 2001; Destaing et al., 2008).

We coelectroporated the SrcY527F or SrcDN expression plasmids with a GFP expression plasmid, or as controls, GFP plasmid alone, in the presumptive lumbar spinal cord at HH st. 18/19 and analyzed LMC cell fate specification and limb axon pathway selection at $\mathrm{HH}$ st. 28/29. The specification and survival of LMC motor neurons were not altered after $\operatorname{SrcY527F}$ or $\operatorname{SrcDN}$ overexpression compared with GFP electroporated controls (supplemental Fig. S5, available at www.jneurosci.org as supplemental material). In addition, the divisional identity of electroporated LMC motor neurons suggested nearly equal proportions of SrcY527F or SrcDN expression in both lateral and medial LMC neurons compared with controls (supplemental Fig. S5, available at www.jneurosci.org as supplemental material). We next analyzed the proportions of $\mathrm{GFP}^{+}$axons within the dorsal and the ventral limb nerves. In embryos coelectroporated with SrcY527F and GFP expression plasmids, a significantly greater proportion of $\mathrm{GFP}^{+}$axons were observed in the ventral limb nerves compared with control embryos: $39 \%$ of $\mathrm{GFP}^{+}$axons were detected in the dorsal and $61 \%$ in the ventral branches (a v/d ratio of 1.6) 


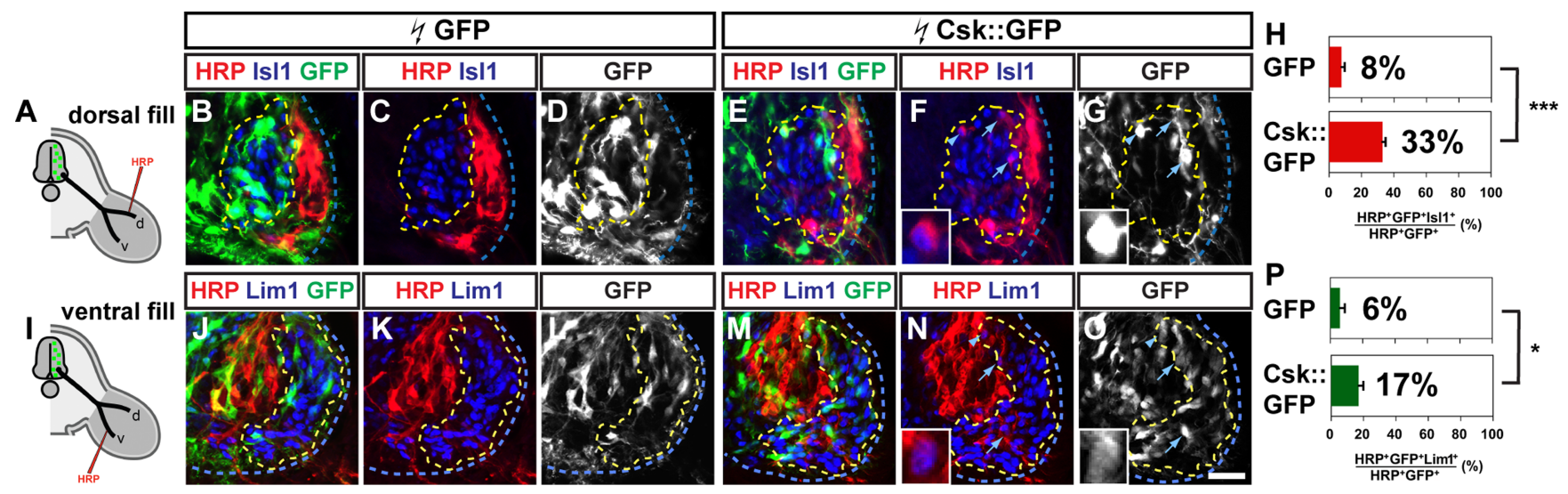

Figure 4. SFK function is required for the fidelity of LMC motor axon limb trajectories. $A, I$, Diagram depicting retrograde labeling of $L M C$ neurons by HRP injections into dorsal $(A)$ or ventral $(I)$ hindlimb shank muscles of chick HH st. 28/29 embryos overexpressing (sk::GFP or GFP. $\boldsymbol{B}-\boldsymbol{G}$, Detection of HRP (red), Isl1 (blue), and GFP (green) in the LMC region of GFP (B-D) or Csk::GFP (E-G) electroporated embryos injected with HRP into dorsal shank muscles. Examples of electroporated medial LMC motor neurons labeled with HRP are indicated by arrows $(\boldsymbol{F}, \boldsymbol{G})$ and arrowheads $(\boldsymbol{F}, \boldsymbol{G})$. Examples indicated by arrowheads are shown at a higher magnification (insets of $\boldsymbol{F}, \boldsymbol{G}$ ). $\boldsymbol{H}$, Proportions (\%) of electroporated medial LMC motor neurons labeled with HRP in embryos injected with HRP into dorsal shank muscles. In dorsally filled GFP expressing embryos, $8 \pm 2 \%$ of $\mathrm{HRP}^{+} \mathrm{GFP}^{+} \mathrm{LMC}$ neurons were Is $11^{+}$. In dorsally filled (sk::GFP expressing embryos, $33 \pm 2 \%$ of HRP ${ }^{+} \mathrm{GFP}{ }^{+}$ $\mathrm{LMC}$ neurons were $\mid \mathrm{Is} 11^{+}$. Number of embryos analyzed: $n=4$ for both GFP and (sk::GFP expressing embryos. J-0, Detection of HRP (red), Lim1 (blue), and GFP (green) in the LMC region of GFP(J-L) or CSk::GFP $(\boldsymbol{M}-\mathbf{O})$ electroporated embryos injected with HRP into ventral shank muscles. Examples of electroporated lateral LMC motor neuron labeled with HRP are indicated by arrows $(\boldsymbol{N}, \mathbf{0})$ and arrowheads $(\boldsymbol{N}, \mathbf{0})$. Examples indicated by arrowheads are shown at a higher magnification (insets of $\boldsymbol{N}, \mathbf{0})$. $\boldsymbol{P}$, Proportions $(\%)$ of electroporated lateral LMC motor neurons labeled with HRP in embryos injected with HRP into ventral shank muscles. In ventrally filled GFP expressing embryos, $6 \pm 5 \%$ of HRP ${ }^{+}$GFP ${ }^{+} \mathrm{LMC}_{\text {neurons were } L i m} 1^{+}$. In ventrally filled Csk::GFP expressing embryos, $17 \pm 3 \%$ of $\mathrm{HRP}^{+} \mathrm{GFP}^{+} \mathrm{LMC}$ neurons were Lim $1^{+}$. Number of embryos quantified: $n=4$ for GFP and Csk::GFP expressing embryos. Proportions of HRP ${ }^{+} \mathrm{GFP}^{+}$medial LMC neurons in dorsally filled Csk::GFP expressing embryos and those in dorsally filled GFP expressing embryos are significantly different $(p<0.001)$ using Student's unpaired t test. Proportions of HRP ${ }^{+}$GFP ${ }^{+}$lateral LMC neurons in ventrally filled (sk::GFP expressing embryos and those in ventrally filled GFP expressing embryos are significantly different $(p<0.05)$ using Student's unpaired $t$ test. Error bars indicate SD. ${ }^{* * *} p<0.001 ;{ }^{*} p<0.05$. All values are expressed as mean \pm SD. Scale bars: $(\boldsymbol{B}-\mathbf{G}, \boldsymbol{J}-\mathbf{0}), 25 \mu \mathrm{m} ;$ or $7 \mu \mathrm{m}$ (insets of $\left.\boldsymbol{F}, \mathbf{G}, \boldsymbol{N}, \mathbf{0}\right)$.

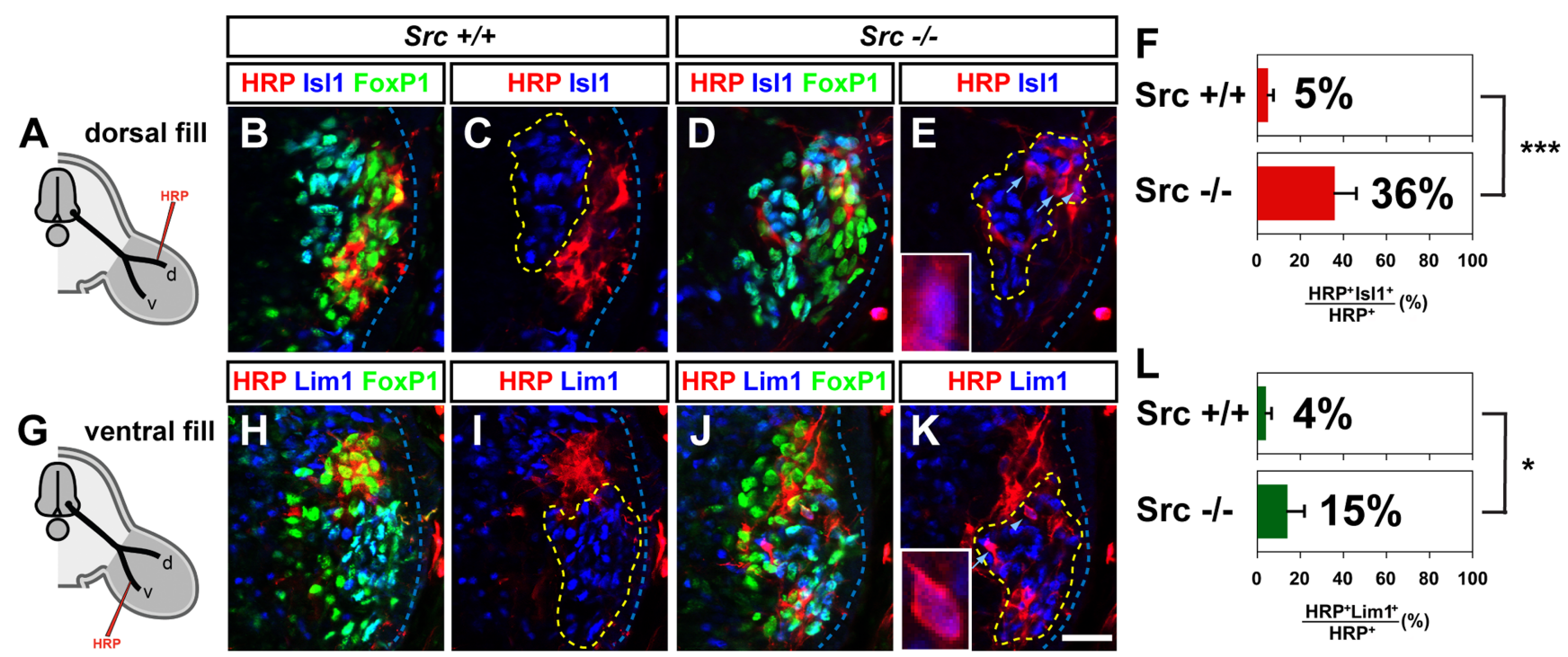

Figure 5. Src is required for the fidelity of $L M C$ motor axon trajectory selection. $\boldsymbol{A}, \mathbf{G}$, Diagram depicting retrograde labeling of $L M C$ neurons by HRP injections into dorsal $(\boldsymbol{A})$ or ventral $(\boldsymbol{G})$ limb muscles of mouse e12.5 embryos. $\boldsymbol{B}-\boldsymbol{E}$, Detection of HRP (red), Is11 (blue), and FoxP1 (green), which marks all LMC motor neurons, in the LMC region of Src ${ }^{+/+}(\boldsymbol{B}, \boldsymbol{C})$ or Src ${ }^{-/-}(\boldsymbol{D}, \boldsymbol{E})$ embryos injected with HRP into dorsal forelimb muscles. Examples of medial LMC motor neurons labeled with HRP are indicated by arrows and arrowheads (E). Examples indicated by arrowheads are shown at a higher magnification (inset of $\boldsymbol{E}$ ). $\boldsymbol{F}$, Proportions (\%) of medial LMC motor neurons labeled with HRP in embryos injected with HRP into dorsal forelimb muscles. In dorsally filled Src ${ }^{+/+}$embryos,

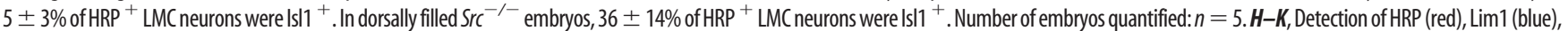
and FoxP1 (green) in the LMC region of $\mathrm{Src}^{+/+}(\boldsymbol{H}, \boldsymbol{I})$ or Src ${ }^{-/-}(\boldsymbol{J}, \boldsymbol{K})$ embryos injected with HRP into ventral forelimb muscles. Examples of lateral LMC motor neurons labeled are indicated by arrows and arrowheads $(\boldsymbol{K})$. Examples indicated by arrowheads are shown at a higher magnification (inset of $\boldsymbol{K}$ ). $\boldsymbol{L}$, Proportions (\%) of lateral LMC motor neurons filled with HRP in embryos injected with HRP into ventral

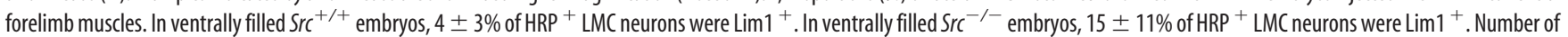
embryos quantified: $n=4$. Proportions of HRP ${ }^{+}$medial LMC neurons in dorsally filled $\mathrm{Src}^{-/-}$embryos and those in dorsally filled $\mathrm{Src}^{+/+}$embryos are significantly different $(p<0.001)$ using Student's unpaired $t$ test. Proportions of $\mathrm{HRP}^{+}$lateral LMC neurons in ventrally filled $\mathrm{Src}^{-/-}$embryos and those in ventrally filled $\mathrm{Src}^{+/+}$embryos are significantly different $(p<0.05)$ using Student's unpaired $t$ test. Error bars $=S D ;{ }^{* *} p<0.001 ;{ }^{*}=p<0.05$; all values expressed as mean \pm SD. Scale bars: $(\boldsymbol{B}-\boldsymbol{E}, \boldsymbol{H}-\boldsymbol{K}), 25 \mu \mathrm{m}$ or (insets of $\left.\boldsymbol{E}, \boldsymbol{K}\right), 7 \mu \mathrm{m}$.

compared with controls in which $52 \%$ and $48 \%$ of $\mathrm{GFP}^{+}$axons were found in, respectively, the ventral and dorsal limb nerves (Fig. 6A-F; a v/d ratio of 0.9 for GFP controls; Student's $t$ test, $p<$ $0.001)$. In contrast, in embryos coelectroporated with $\operatorname{SrcDN}$ and
GFP expression plasmids, a significant greater fraction of GFP axons were observed in the dorsal limb nerves when compared with controls: $64 \%$ of $\mathrm{GFP}^{+}$axons were detected in the dorsal and $36 \%$ in the ventral limb nerves (Fig. $6 G-I$; a v/d ratio of 0.6 ; 
Student's $t$ test, $p<0.001)$. These observations indicate that blocking Src activity directs more LMC axons into the dorsal limb nerve, consistent with the altered limb axon trajectory selection by LMC axons overexpressing Csk or lacking $S r c$ function, and increasing the level of Src activity results in redirection of LMC axons into the ventral limb nerve.

\section{SFK function is required for Eph signaling-induced LMC motor axon redirection}

SFKs have been suggested as downstream effectors of Eph signaling in several contexts (Knöll and Drescher, 2004; Zimmer et al., 2007). Also, ephrin:Eph signaling is sufficient to redirect LMC axons: overexpression of EphA4 in LMC axons results in almost all of them projecting into the dorsal limb nerve (Kania and Jessell, 2003; Luria et al., 2008). To examine whether SFKs might play a role in Eph signal transduction during LMC motor axon pathfinding, we coelectroporated the Eph receptor-GFP fusion protein expression plasmids EphB2::GFP or EphA4::GFP with Csk expression plasmids and compared with control EphB2::GFP or EphA4::GFP plasmid electroporations. The in ovo electroporations were performed in the presumptive lumbar spinal cord at $\mathrm{HH}$ st. $18 / 19$ and analyzed at $\mathrm{HH}$ st. 28/29. In control embryos electroporated with EphB2::GFP alone, a higher fraction of $\mathrm{GFP}^{+}$axons was observed in ventral LMC axons when compared with GFP alone controls: $35 \%$ of $\mathrm{GFP}^{+}$axons were detected in the dorsal and $65 \%$ in the ventral limb nerves, demonstrating that EphB2 over-expression is sufficient to redirect LMC axons into the ventral limb (Figs. $6 A-C, A-C$; a v/d ratio of 1.9; Student's $t$ test, $p<0.001$ vs GFP controls). In embryos coelectroporated with $C s k$ and EphB2::GFP, significant higher proportions of GFP levels were observed in dorsal nerve branches compared with EphB2::GFP alone: $52 \%$ of GFP ${ }^{+}$axons in the dorsal and $48 \%$ in the ventral branches, and the v/d ratio decreased to 0.9 (Fig. $7 D-F$; Student's $t$ test, $p<0.001$ vs EphB2::GFP). This result indicates that inhibition of SFK function attenuates EphB2-induced LMC motor axon redirection.

EphA4::GFP over-expression in control embryos, as previously demonstrated (Eberhart et al., 2002; Kania and Jessell, 2003), induced a robust redirection of LMC axons into the dorsal limb nerves: $91 \%$ of $\mathrm{GFP}^{+}$axons were detected in dorsal and only $9 \%$ in the ventral branches (Fig. 7G-I; a v/d ratio of 0.1 ; Student's $t$ test, $p<0.001$ vs GFP controls). In embryos coelectroporated with $C s k$ and EphA4::GFP, proportions of axonal GFP levels were significant increased in ventral branches compared with EphA4::GFP electroporated controls: $76 \%$ of $\mathrm{GFP}^{+}$axons were detected in the dorsal and $24 \%$ in the ventral branches, and the v/d ratio increased to 0.3 (Fig. $7 J-L$; Student's $t$ test, $p<0.001$ ). These observations indicate that SFK inhibition attenuates EphA4-induced LMC motor axon redirection.

EphA4 receptors are thought to recruit several SFKs through juxtamembrane tyrosine residues, and a glutamic acid mutation at one of the conserved juxtamembrane tyrosines (Y602E) was shown to eliminate SH2 domain interactions (Ellis et al., 1996; Zisch et al., 1998, 2000). To test whether the juxtamembrane tyrosine is required for EphA4 function in LMC axon guidance, we over-expressed this EphA4 mutant (EphA4Y602E) by coelectroporating EphA4Y602E and GFP expression plasmids or control EphA4 and GFP plasmids in the presumptive lumbar spinal cord at HH st. 18/19 and analyzed LMC axon trajectory selection at $\mathrm{HH}$ st. 28/29. The specification and survival of LMC motor neurons were not altered after EphA4 or EphA4Y602E overexpression compared with GFP electroporated embryos (supplemental Fig. S6, available at www.jneurosci.org as supplemental material). In embryos coelectroporated with EphA4 and GFP expression plasmids, as expected, LMC axons were redirected into the dorsal limb: $85 \%$ of GFP ${ }^{+}$axons were detected in the dorsal and $15 \%$ in the ventral limb nerves (Fig. $7 \mathrm{M}-\mathrm{O}$; a v/d ratio of 0.2 ; Student's $t$ test, $p<0.001$ vs GFP controls). In embryos coelectroporated with EphA4Y602E and GFP expression plasmids, however, a complete block of EphA4 function was observed compared with EphA4 and GFP coelectroporated embryos: the proportion of $\mathrm{GFP}^{+}$axon detected in dorsal and ventral limb nerves was $59 \%$ and $41 \%$, respectively (Fig. $7 P-R$; a v/d ratio of 0.7 ; Student's $t$ test, $p<0.001$ vs EphA4 and GFP) which was not significantly different from GFP electroporation alone (Student's $t$ test, $p=0.061)$. These findings suggest that Y602 in EphA4 receptors, a potential SFK binding site, is essential for in vivo EphA4 function in LMC axon trajectory redirection. 


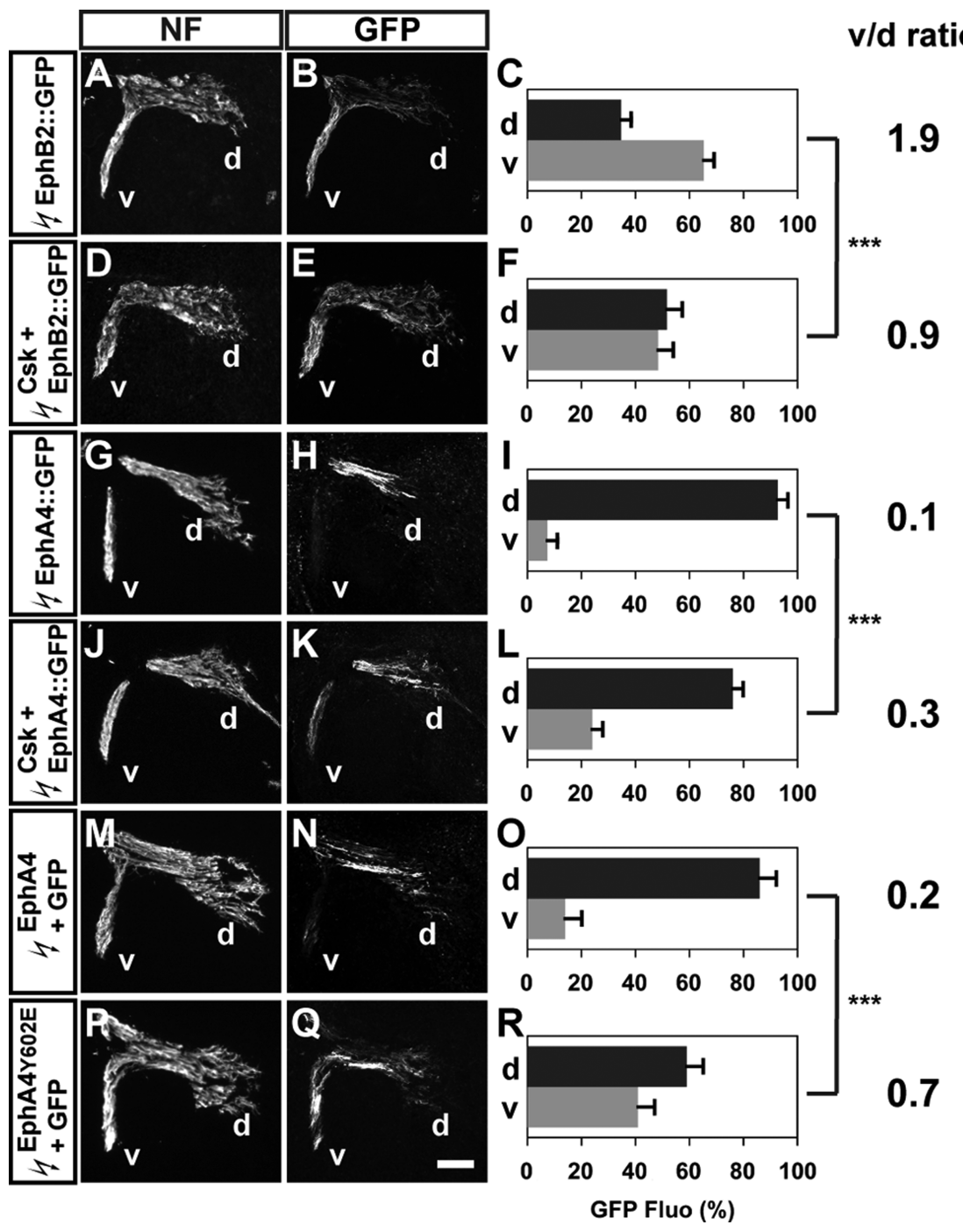

Figure 7. SFK inhibition by Csk attenuates EphB2- and EphA4-induced $L M C$ motor axon redirection. $A, D, G, J, M, P$, Neurofilament detection in the limb nerves of chick HH st. 28/29 EphB2::GFP (A), Csk and EphB2::GFP (D), EphA4::GFP (G), Csk and EphA4::GFP $(\boldsymbol{J})$, EphA4 and GFP $(\boldsymbol{M})$, or EphA4Y602E and GFP $(\boldsymbol{P})$ expressing embryos. $\boldsymbol{B}, \boldsymbol{E}, \boldsymbol{H}, \boldsymbol{K}, \boldsymbol{N}, \boldsymbol{Q}, \mathbf{G F P}$ detection in the limb nerves of HH st. 28/29 EphB2:::GFP (B), Csk and EphB2::GFP (E), EphA4::GFP (H), Csk and EphA4::GFP $(\boldsymbol{K})$, EphA4 and GFP $(\boldsymbol{N})$, or EphA4Y602E and GFP ( $(\mathbf{Q})$ expressing embryos. $C, F, I, L, O, R$, Quantification of GFP ${ }^{+}$axons within dorsal and ventral limb nerves expressed as the percentage of total GFP ${ }^{+}$axons [GFP Fluo (\%)]. In EphB2::GFP electroporated embryos, $35 \pm 4 \%$ of GFP ${ }^{+}$axons were detected in the dorsal limb nerves, and $65 \pm 4 \%$ of GFP ${ }^{+}$axons were detected in the ventral limb nerves ( $v / d$ ratio of 1.9; C. In Csk and EphB2:::GFP coelectroporated embryos, $52 \pm 6 \%$ of GFP ${ }^{+}$axons were detected in the dorsal limb nerves, and $48 \pm$ $6 \%$ of GFP ${ }^{+}$axons were detected in the ventral limb nerves (v/d ratio of $\left.0.9 ; \boldsymbol{F}\right)$. In EphA4::GFP electroporated embry0s, $91 \pm 4 \%$ of $\mathrm{GFP}^{+}$axons were detected in the dorsal limb nerves, and $9 \pm 4 \%$ of $\mathrm{GFP}^{+}$axons were detected in the ventral limb nerves ( $\mathrm{v} / \mathrm{d}$ ratio of $0.1 ; I)$. In (sk and EphA4.:GFP coelectroporated embryos, $76 \pm 4 \%$ of GFP ${ }^{+}$axons were detected in the dorsal limb nerves, and $24 \pm 4 \%$ of GFP ${ }^{+}$axons were detected in the ventral limb nerves (v/d ratio of $0.3 ; L$ ). In EphA4 and GFP coelectroporated embryos, $85 \pm 6 \%$ of GFP ${ }^{+}$axons were detected in the dorsal limb nerves, and $15 \pm 6 \%$ of GFP $^{+}$axons were detected in the ventral limb nerves ( $\mathrm{v} / \mathrm{d}$ ratio of $0.2 ; 0)$. In EphA4Y602E and GFP coelectroporated embryos, $59 \pm 6 \%$ of GFP $^{+}$axons were detected in the dorsal limb nerves, and $41 \pm 6 \%$ of GFP ${ }^{+}$axons were detected in the ventral limb nerves ( $\mathrm{V} / \mathrm{d}$ ratio of $0.7 ; \boldsymbol{R}$ ). Number of embryos quantified: $\boldsymbol{C}, n=8 ; \boldsymbol{F}, n=9 ; \boldsymbol{I}, n=8 ; \boldsymbol{L}, n=7 ; \mathbf{O}, n=5 ; \boldsymbol{R}, n=4$. Proportions of GFP ${ }^{+}$axons in Csk and EphB2::GFP expressing embryos and those in EphB2::GFP expressing embryos are significantly different $(p<0.001)$ using Student's unpaired $t$ test. Proportions of GFP ${ }^{+}$axons in Csk and EphA4::GFP expressing embryos and those in EphA4::GFP expressing embryos are significantly different $\left(p<0.001\right.$ ) using Student's unpaired $t$ test. Proportions of GFP ${ }^{+}$axons in EphA4Y602E and GFP expressing embryos and those in EphA4 and GFP expressing embryos are significantly different $(p<0.001)$ using Student's unpaired $t$ test. $v / d$ ratio $=$ (average ventral GFP Fluo \%)/(average dorsal GFP Fluo \%); NF, neurofilament; $d$, dorsal; $v$, ventral; error bars $=S D .{ }^{* *} p<0.001$; all values expressed as mean \pm SD. Scale bar, $100 \mu \mathrm{m}$ in all images.

\section{Discussion}

SFKs have been proposed to function in signaling pathways essential for axon outgrowth and guidance. We investigated these potential roles in vivo and found that SFKs are essential for the fidelity of motor axon trajectory selection in the limb. Here we discuss the differential requirement of SFK function by LMC subpopulations, the dispensable role of SFKs in axon outgrowth, SFK functional redundancy and the potential role of SFKs in Eph receptor signal relay.

SFKs are dispensable for motor axon outgrowth but are essential for guidance SFKs have been proposed to be important modulators of neurite extension: SFK over-expression lengthens filopodia and active Src is colocalized with Cdc42 at the tips of growth cone filopodia where it has been proposed to regulate the p21activated kinase, a Cdc42 effector (Robles et al., 2005; Wu et al., 2008). Interestingly, we did not observe obvious changes in axon outgrowth of limb nerves in Src mutants or chick embryos with attenuated or enhanced SFK activity in LMC neurons. Although we cannot exclude the possibility that the residual SFK function not blocked by Csk is sufficient to mediate axon outgrowth, or that in Src mutants, Fyn substitutes for Src function, contrary to previous in vitro studies, SFK activity appears to have limited effect on motor axon outgrowth. Furthermore, although SFKs have been implicated in fasciculation (Morse et al., 1998), the lack of gross fasciculation defects in SFK loss of function conditions suggest that they are dispensable for this process in motor axons.

Our demonstration that SFKs are required for LMC axon guidance raises the question of how they might relay guidance signals to the cytoskeleton. SFK targets like Vav2 and chimaerins are implicated in growth cone collapse/turning but not in extension, and some like ephexin and kalirin are implicated in both processes (Cowan et al., 2005; Rabiner et al., 2005; Sahin et al., 2005; Schiller et al., 2006; Beg et al., 2007; Wegmeyer et al., 2007). Presumably, the interaction of SFKs with these targets is essential for growth cone steering, thus, a general model of SFK function in axon guidance could first involve SFK interaction with the intracellular domain of a guidance receptor engaged by ligand, followed by phosphorylation of SFK targets including guanine nucleotide exchange factors (GEFs) or GTPase activating proteins. The activation of SFK targets, such as $\alpha 2$-chimaerin and Vav2, is then required for localized small GTPase activity resulting in growth cone turning, as suggested by observations of aberrant midline crossing of spinal interneuron axons in $\alpha 2$-chimaerin mutants and the retinogeniculate projection defects in Vav2 mutants (Cowan et al., 2005; Beg et al., 2007). Intriguingly, $\alpha 2$-chimaerin, Nck1 and 
Nck2 are expressed in spinal motor neurons when axons grow into the limb suggesting that they could relay SFK signals in LMC growth cones in the limb (Hall et al., 2001; Bladt et al., 2003).

Our data provide strong evidence that although Src and Fyn are expressed in essentially all LMC neurons, their requirement for the fidelity of LMC axon trajectory selection appears differential: medial LMC axon guidance appears to depend on SFK function to a greater extent than lateral LMC axon guidance. A study by Knöll and Drescher (2004) also describes a differential requirement of SFKs by retinal neurons. Despite similar SFK levels in the temporal and nasal retinal axons, SFK inhibition induces different effects on temporal and nasal axons, implying that nasal, but not temporal, axon guidance relies on SFK signaling. In LMC neurons, the differential SFK requirement could be due to different pathways being required for guidance of either LMC subgroups. Ample evidence has implicated EphA and EphB signaling in guidance of lateral and medial LMC axons, respectively (Kania and Jessell, 2003; Luria et al., 2008) and the differential sensitivity of lateral and medial LMC neurons to SFK loss could reflect the differential requirement of SFKs in EphA and EphB receptor signaling. However, since we do not know the extent of Csk and SFK protein coexpression in LMC neurons it may be that lateral LMC neurons contain much higher levels of Csk protein than medial LMC neurons, making them less sensitive to SFK function loss.

\section{The nonredundant function of Src in motor axon trajectory selection}

In embryonic fibroblasts, Src but not Fyn regulates cortactin and tensin hyperphosphorylation (Nada et al., 1993; Thomas et al., 1995). Fyn is nonredundant with Src in oligodendrocytes such that Fyn but not Src mutants show a forebrain myelin defect (Sperber et al., 2001). Although known for a specific role in bone formation (Soriano et al., 1991), Src is redundant with other SFKs in cytoskeleton rearrangement such as neuronal migration (Kuo et al., 2005). In contrast, our studies demonstrate that Src mutants display strong LMC axon guidance defects suggesting a differential requirement of Src and Fyn in motor axon guidance. The distinct role among coexpressed SFKs may be enabled by their unique N-terminal domains, which could allow them to reside in different compartments of the growth cone membrane, as implied by studies showing that SFKs are required to form different types of lipid membrane microdomains (Lovatt et al., 2006; Yamazaki et al., 2007).

\section{SFK function in ephrin:Eph signaling}

Our experiments implicating SFKs in EphA signaling are in concert with previous observations in retinal neurons suggesting that SFKs are important for EphA-mediated axon guidance (Knöll and Drescher, 2004). There are, however, differences between these systems, including graded versus discrete expression of Ephs and ephrins in the retinotectal and motor system, and the concerted control of axon projections by EphA and EphB signaling within all retinotectal axons and their dominance in nonoverlapping subsets of motor axons. In fact, it is the discrete expression and involvement of EphA and EphB signaling in two populations of motor neurons that allows us to decipher the downstream mechanisms of both Eph pathways separately.

Indeed, our data showing differential requirement of SFKs in ephrin:Eph signaling-mediated motor axon guidance suggest that SFKs play an important role in EphB-mediated medial LMC axon trajectory selection and only a partial role in EphA-mediated lateral LMC axon trajectory selection. SFK targets involved in either Eph pathway may be responsible for the differential SFK requirement: the Rho family GEF, kalirin, and the focal adhesion kinase, paxillin, modulate cytoskeleton dynamics as EphB but not EphA effectors (Penzes et al., 2003; Vindis et al., 2004; Moeller et al., 2006). Other effectors, such as Nck and Vav2, however, can interact with both Eph pathways to modulate growth cone motility (Cowan et al., 2005; Wegmeyer et al., 2007). The different extent of Src involvement in either Eph pathway could thus be dependent on the differential requirement of these effectors.

Another explanation for the partial requirement of SFKs in lateral LMC axon guidance is that SFKs are redundant with other EphA effectors participating in lateral LMC axon guidance or that SFKs are only required for the guidance of lateral LMC subpopulation. Due to a later termination of migration and differentiation of lateral LMC neurons, a competition for common effectors like SFKs involved in multiple functions in addition to axon guidance, such as cell migration and differentiation, could result in a partial dependence of SFKs in lateral LMC axon trajectory. However, our findings demonstrating no obvious change of cell identity, survival, positions, and morphology in both LMC divisions imply little impact of SFKs on cell migration and differentiation. Other than their role as Eph effectors, SFKs have been suggested to be involved in GDNF:c-Ret signaling (Tansey et al., 2000; Encinas et al., 2001). Interestingly, previous studies have implicated the requirement of GDNF/c-RET signaling for targeting of some lateral LMC axons (Kramer et al., 2006). Because of a potential coordination between c-RET and Eph signaling to mediate motor axon guidance (Kramer et al., 2006), a proportion of SFKsensitive lateral LMC axon could be involved in c-Ret signaling.

Among those signaling pathways implicated in regulating motor axon guidance, the pervasive effect of Eph signaling on LMC axon trajectories suggests that Eph signaling serves an obligate role in LMC axon guidance (Helmbacher et al., 2000; Luria et al., 2008). Our findings demonstrating the requirement of a juxtamembrane domain tyrosine (Y602E) for EphA4-mediated axonal repulsion supports the essential role of SFKs in motor axon guidance. Although we cannot exclude the possibility of incomplete SFK inactivation by Csk, the stronger effect of abolishing EphA4-induced axon redirection by EphA4Y602E compared with that of Csk over-expression may be because of interactions of Y602 with other Eph signal relay components such as Nck, $\alpha 2$-chimaerin, or Vav2. Nevertheless, the activities of these molecules are SFK dependent (Cowan et al., 2005; Bisson et al., 2007; Wegmeyer et al., 2007).

\section{Conclusion}

Here we show that SFKs are required for motor axon trajectory selection but appear dispensable for motor axon outgrowth. This is the first report pointing to an important role of SFKs in Ephregulated motor axon guidance in vivo, highlighting the importance of the LMC motor axon projection system as a model of a simple axon guidance decision in which the roles of receptor signaling relay machinery can be investigated.

\section{References}

Beg AA, Sommer JE, Martin JH, Scheiffele P (2007) $\alpha 2$-Chimaerin is an essential EphA4 effector in the assembly of neuronal locomotor circuits. Neuron 55:768-778.

Bisson N, Poitras L, Mikryukov A, Tremblay M, Moss T (2007) EphA4 signaling regulates blastomere adhesion in the Xenopus embryo by recruiting Pak1 to suppress Cdc42 function. Mol Biol Cell 18:1030-1043.

Bladt F, Aippersbach E, Gelkop S, Strasser GA, Nash P, Tafuri A, Gertler FB, Pawson T (2003) The murine Nck SH2/SH3 adaptors are important for 
the development of mesoderm-derived embryonic structures and for regulating the cellular actin network. Mol Cell Biol 23:4586-4597.

Cowan CW, Shao YR, Sahin M, Shamah SM, Lin MZ, Greer PL, Gao S, Griffith EC, Brugge JS, Greenberg ME (2005) Vav family GEFs link activated Ephs to endocytosis and axon guidance. Neuron 46:205-217.

Cursi S, Rufini A, Stagni V, Condò I, Matafora V, Bachi A, Bonifazi AP, Coppola L, Superti-Furga G, Testi R, Barilà D (2006) Src kinase phosphorylates Caspase- 8 on Tyr380: a novel mechanism of apoptosis suppression. EMBO J 25:1895-1905.

Dasen JS, Decamilli A, Wang B, Tucker PW, Jessell TM (2008) Hox repertoires for motor neuron diversity and connectivity gated by a single accessory factor, FoxP1. Cell 134:304-316.

Destaing O, Sanjay A, Itzstein C, Horne WC, Toomre D, De Camilli P, Baron R (2008) The tyrosine kinase activity of c-Src regulates actin dynamics and organization of podosomes in osteoclasts. Mol Biol Cell 19:394-404.

Dodd J, Jessell TM (1988) Axon guidance and the patterning of neuronal projections in vertebrates. Science 242:692-699.

Eberhart J, Swartz ME, Koblar SA, Pasquale EB, Krull CE (2002) EphA4 constitutes a population-specific guidance cue for motor neurons. Dev Biol 247:89-101.

Ellis C, Kasmi F, Ganju P, Walls E, Panayotou G, Reith AD (1996) A juxtamembrane autophosphorylation site in the Eph family receptor tyrosine kinase, Sek, mediates high affinity interaction with p59fyn. Oncogene 12:1727-1736.

Encinas M, Tansey MG, Tsui-Pierchala BA, Comella JX, Milbrandt J, Johnson EM Jr (2001) c-Src is required for glial cell line-derived neurotrophic factor (GDNF) family ligand-mediated neuronal survival via a phosphatidylinositol-3 kinase (PI-3K)-dependent pathway. J Neurosci $21: 1464-1472$.

Erpel T, Superti-Furga G, Courtneidge SA (1995) Mutational analysis of the Src SH3 domain: the same residues of the ligand binding surface are important for intra- and intermolecular interactions. EMBO J 14:963-975.

Fawcett JP, Georgiou J, Ruston J, Bladt F, Sherman Am Warner N, Saab BJ, Scott R, Roder JC, Pawson T (2007) Nck adaptor proteins control the organization of neuronal circuits important for walking. Proc Natl Acad Sci U S A 104:20973-20978.

Fresno Vara JA, Cáceres MA, Silva A, Martin-Pérez J (2001) Src family kinases are required for prolactin induction of cell proliferation. Mol Biol Cell 12:2171-2183.

Hall C, Michael GJ, Cann N, Ferrari G, Teo M, Jacobs T, Monfries C, Lim L (2001) alpha2-chimaerin, a Cdc42/Rac1 regulator, is selectively expressed in the rat embryonic nervous system and is involved in neuritogenesis in N1E-115 neuroblastoma cells. J Neurosci 21:5191-5202.

Hamburger V, Hamilton HL (1951) A series of normal stages in the development of the chick embryo. J Morphol 88:195-272.

Helmbacher F, Schneider-Maunoury S, Topilko P, Tiret L, Charnay P (2000) Targeting of the EphA4 tyrosine kinase receptor affects dorsal/ventral pathfinding of limb motor axons. Development 127:3313-3324.

Hoffman-Kim D, Kerner JA, Chen A, Xu A, Wang TF, Jay DG (2002) pp60csrc is a negative regulator of laminin-1-mediated neurite outgrowth in chick sensory neurons. Mol Cell Neurosci 21:81-93.

Itoh B, Hirose T, Takata N, Nishiwaki K, Koga M, Ohshima Y, Okada M (2005) SRC-1, a non-receptor type of protein tyrosine kinase, controls the direction of cell and growth cone migration in C. elegans Development 132:5161-5172.

Kania A, Jessell TM (2003) Topographic motor projections in the limb imposed by LIM homeodomain protein regulation of ephrin-A:EphA interactions. Neuron 38:581-596.

Kania A, Johnson RL, Jessell TM (2000) Coordinate roles for LIM homeobox genes in directing the dorsoventral trajectory of motor axons in the vertebrate limb. Cell 102:161-173.

Klages S, Adam D, Class K, Fargnoli J, Bolen JB, Penhallow RC (1994) Ctk: a protein-tyrosine kinase related to Csk that defines an enzyme family. Proc Natl Acad Sci U S A 91:2597-2601.

Knöll B, Drescher U (2004) Src family kinases are involved in EphA receptor-mediated retinal axon guidance. J Neurosci 24:6248-6257.

Kramer ER, Knott L, Su F, Dessaud E, Krull CE, Helmbacher F, Klein R (2006) Cooperation between GDNF/Ret and ephrinA/EphA4 signals for motor-axon pathway selection in the limb. Neuron 50:35-47.

Kuo G, Arnaud L, Kronstad-O’Brien P, Cooper JA (2005) Absence of Fyn and Src causes a reeler-like phenotype. J Neurosci 25:8578-8586.
Kuo WL, Chung KC, Rosner MR (1997) Differentiation of central nervous system neuronal cells by fibroblast-derived growth factor requires at least two signaling pathways: roles for Ras and Src. Mol Cell Biol 17:4633-4643.

Lance-Jones C, Landmesser L (1981) Pathway selection by embryonic chick motoneurons in an experimentally altered environment. Proc R Soc Lond B Biol Sci 214:19-52.

Landmesser L (1978) The development of motor projection patterns in the chick hind limb. J Physiol 284:391-414.

Lee SK, Jurata LW, Funahashi J, Ruiz EC, Pfaff SL (2004) Analysis of embryonic motoneuron gene regulation: derepression of general activators function in concert with enhancer factors. Development 131:3295-3306.

Liu G, Li W, Gao X, Li X, Jürgensen C, Park HT, Shin NY, Yu J, He ML, Hanks SK, Wu JY, Guan KL, Rao Y (2007) p130CAS is required for netrin signaling and commissural axon guidance. J Neurosci 27:957-968.

Lovatt M, Filby A, Parravicini V, Werlen G, Palmer E, Zamoyska R (2006) Lck regulates the threshold of activation in primary T cells, while both Lck and Fyn contribute to the magnitude of the extracellular signal-related kinase response. Mol Cell Biol 26:8655-8665.

Luria V, Laufer E (2007) Lateral motor column axons execute a ternary trajectory choice between limb and body tissues. Neural Dev 2:13.

Luria V, Krawchuk D, Jessell TM, Laufer E, Kania A (2008) Specification of motor axon trajectory by ephrin-B:EphB signaling: symmetrical control of axonal patterning in the developing limb. Neuron 60:1039-1053.

Martin GS (2001) The hunting of the Src. Nat Rev Mol Cell Biol 2:467-475.

Meriane M, Tcherkezian J, Webber CA, Danek EI, Triki I, McFarlane S, Bloch-Gallego E, Lamarche-Vane N (2004) Phosphorylation of DCC by Fyn mediates Netrin-1 signaling in growth cone guidance. J Cell Biol 167:687-698.

Moeller ML, Shi Y, Reichardt LF, Ethell IM (2006) EphB receptors regulate dendritic spine morphogenesis through the recruitment/phosphorylation of focal adhesion kinase and RhoA activation. J Biol Chem 281:1587-1598.

Momose T, Tonegawa A, Takeuchi J, Ogawa H, Umesono K, Yasuda K (1999) Efficient targeting of gene expression in chick embryos by microelectroporation. Dev Growth Differ 41:335-344.

Morse WR, Whitesides JG 3rd, LaMantia AS, Maness PF (1998) p 59 fyn and pp $60 \mathrm{c}$-src modulate axonal guidance in the developing mouse olfactory pathway. J Neurobiol 36:53-63.

Nada S, Yagi T, Takeda H, Tokunaga T, Nakagawa H, Ikawa Y, Okada M, Aizawa S (1993) Constitutive activation of Src family kinases in mouse embryos that lack Csk. Cell 73:1125-1135.

Penzes P, Beeser A, Chernoff J, Schiller MR, Eipper BA, Mains RE, Huganir RL (2003) Rapid induction of dendritic spine morphogenesis by transsynaptic EphrinB-EphB receptor activation of the Rho-GEF Kalirin. Neuron 37:263-274.

Rabiner CA, Mains RE, Eipper BA (2005) Kalirin: A dual rho guanine nucleotide exchange factor that is so much more than the sum of its many parts. Neuroscientist 11:148-160.

Robles E, Woo S, Gomez TM (2005) Src-dependent tyrosine phosphorylation at the tips of growth cone filopodia promotes extension. J Neurosci 25:7669-7681.

Rozen S, Skaletsky H (2000) Primer3 on the WWW for general users and for biologist programmers. Methods Mol Biol 132:365-386.

Sabe H, Knudsen B, Okada M, Nada S, Nakagawa H (1992) Molecular cloning and expression of chicken C-terminal Src kinase: lack of stable association with c-Src protein. Proc Natl Acad Sci U S A 89:2190-2194.

Sahin M, Greer PL, Lin MZ, Poucher H, Eberhart J, Schmidt S, Wright TM, Shamah SM, O'connell S, Cowan CW, Hu L, Goldberg JL, Debant A, Corfas G, Krull CE, Greenberg ME (2005) Eph-dependent tyrosine phosphorylation of ephexin1 modulates growth cone collapse. Neuron 46:191-204.

Sasaki Y, Cheng C, Uchida Y, Nakajima O, Ohshima T, Yagi T, Taniguchi M, Nakayama T, Kishida R, Kudo Y, Ohno S, Nakamura F, Goshima Y (2002) Fyn and Cdk5 mediate semaphorin-3A signaling, which is involved in regulation of dendrite orientation in cerebral cortex. Neuron 35:907-920.

Schaeren-Wiemers N, Gerfin-Moser A (1993) A single protocol to detect transcripts of various types and expression levels in neural tissue and cultured cells: in situ hybridization using digoxigenin-labelled cRNA probes. Histochemistry 100:431-440.

Schiller MR, Chakrabarti K, King GF, Schiller NI, Eipper BA, Maciejewski 
MW (2006) Regulation of rhoGEF activity by intramolecular and intermolecular SH3 domain interactions. J Biol Chem 281:18774-18786.

Soriano P, Montgomery C, Geske R, Bradley A (1991) Targeted disruption of the c-src proto-oncogene leads to osteopetrosis in mice. Cell 64:693-702.

Sperber BR, Boyle-Walsh EA, Engleka MJ, Gadue P, Peterson AC, Stein PL, Scherer SS, McMorris FA (2001) A unique role for Fyn in CNS myelination. J Neurosci 21:2039-2047.

Stein PL, Vogel H, Soriano P (1994) Combined deficiencies of Src, Fyn, and Yes tyrosine kinases in mutant mice. Genes Dev 8:1999-2007.

Tansey MG, Baloh RH, Milbrandt J, Johnson EM Jr (2000) GFRalphamediated localization of RET to lipid rafts is required for effective downstream signaling, differentiation, and neuronal survival. Neuron 25:611-623.

Thomas SM, Brugge JS (1997) Cellular functions regulated by SRC family kinases. Annu Rev Cell Dev Biol 13:513-609.

Thomas SM, Soriano P, Imamoto A (1995) Specific and redundant roles of Src and Fyn in organizing the cytoskeleton. Nature 376:267-271.

Tosney KW, Landmesser LT (1985) Development of the major pathways for neurite outgrowth in the chick hindlimb. Dev Biol 109:193-214.

Tsuchida T, Ensini M, Morton SB, Baldassare M, Edlund T, Jessell TM, Pfaff SL (1994) Topographic organization of embryonic motor neurons defined by expression of LIM homeobox genes. Cell 79:957-970.

Uemura O, Okada Y, Ando H, Guedj M, Higashijima S, Shimazaki T, Chino $\mathrm{N}$, Okano H, Okamoto H (2005) Comparative functional genomics revealed conservation and diversification of three enhancers of the gene for motor and sensory neuron-specific expression. Dev Biol 278:587-606.

Vindis C, Teli T, Cerretti DP, Turner CE, Huynh-Do U (2004) EphB1mediated cell migration requires the phosphorylation of paxillin at Tyr31/Tyr-118. J Biol Chem 279:27965-27970.

Wegmeyer H, Egea J, Rabe N, Gezelius H, Filosa A, Enjin A, Varoqueaux F, Deininger K, Schnütgen F, Brose N, Klein R, Kullander K, Betz A (2007)
EphA4-dependent axon guidance is mediated by the RacGAP $\alpha 2$ chimaerin. Neuron 55:756-767.

Wouda RR, Bansraj MR, de Jong AW, Noordermeer JN, Fradkin LG (2008) Src family kinases are required for WNT5 signaling through the derailed/ RYK receptor in the Drosophila embryonic central nervous system. Development 135:2277-2287.

Wu B, Decourt B, Zabidi MA, Wuethrich LT, Kim WH, Zhou Z, MacIsaac K, Suter DM (2008) Microtubule-mediated Src tyrosine kinase trafficking in neuronal growth cones. Mol Biol Cell 19:4611-4627.

Yamazaki Y, Horibata Y, Nagatsuka Y, Hirabayashi Y, Hashikawa T (2007) Fucoganglioside $\alpha$-fucosyl( $\alpha$-galactosyl)-GM1: a novel member of lipid membrane microdomain components involved in PC12 cell neuritogenesis. Biochem J 407:31-40.

Yue X, Dreyfus C, Kong TA, Zhou R (2008) A subset of signal transduction pathways is required for hippocampal growth cone collapse induced by ephrin-A5. Dev Neurobiol 68:1269-1286.

Zhou L, Martinez SJ, Haber M, Jones EV, Bouvier D, Doucet G, Corera AT, Fon EA, Zisch AH, Murai KK (2007) EphA4 signaling regulates phospholipase $\mathrm{C} 1$ activation, cofilin membrane association, and dendritic spine morphology. J Neurosci 27:5127-5138.

Zimmer G, Kästner B, Weth F, Bolz J (2007) Multiple effects of ephrin-A5 on cortical neurons are mediated by Src family kinases. J Neurosci 27:5643-5653.

Zisch AH, Kalo MS, Chong LD, Pasquale EB (1998) Complex formation between EphB2 and Src requires phosphorylation of tyrosine 611 in the EphB2 juxtamembrane region. Oncogene 16:2657-2670.

Zisch AH, Pazzagli C, Freeman AL, Schneller M, Hadman M, Smith JW, Ruoslahti E, Pasquale EB (2000) Replacing two conserved tyrosines of the EphB2 receptor with glutamic acid prevents binding of $\mathrm{SH} 2$ domains without abrogating kinase activity and biological responses. Oncogene 19:177-187. 